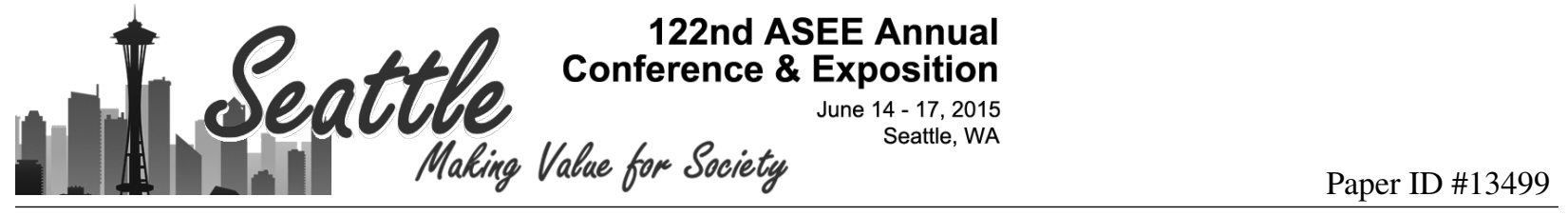

\title{
Nanotechnology Courses for General Education
}

\section{Prof. James E Morris, Portland State University}

Jim is a Professor of Electrical \& Computer Engineering at Portland State University, Oregon, USA, with B.Sc. and M.Sc. degrees in Physics from the University of Auckland, New Zealand, and a Ph.D. in Electrical Engineering from the University of Saskatchewan, Canada. He has served as Department Chair at both SUNY-Binghamton and PSU, and was the founding Director of Binghamton's Institute for Research in Electronics Packaging. Jim has held multiple visiting faculty positions around the world, notably as a Royal Academy of Engineering Distinguished Visiting Fellow at Loughborough University (UK), as a Nokia-Fulbright Fellow at the Helsinki University of Technology, and as an Erskine Fellow at the University of Canterbury (NZ). Other positions have included periods at Delphi Engineering (NZ) and IBM-Endicott (NY), industrial consulting, and as a Senior Technician at the U of S. Jim is an IEEE Life Fellow and an IEEE Components, Packaging, \& Manufacturing (CPMT) Society Distinguished Lecturer. He has served as CPMT Treasurer (1991-1997) and Vice-President for Conferences (1998-2003), and currently sits on the CPMT Board of Governors (1996-1998, 2011-2016) and the Oregon joint CPMT/CAS Chapter Exec and chairs the CPMT Nanotechnology technical committee. He was awarded the IEEE Millennium Medal and won the 2005 CPMT David Feldman Outstanding Contribution Award. He is an Associate-Editor of the IEEE CPMT Transactions and has been General Chair of three IEEE conferences, Treasurer or Program Chair of others, and serves on several CPMT conference committees. As the CPMT Society representative on the IEEE Nanotechnology Council (NTC), he instituted a regular Nanopackaging series of articles in the IEEE Nanotechnology Magazine, established the NTC Nanopackaging technical committee, was the 2010-2013 NTC Awards Chair, chaired the IEEE NANO 2011 conference, serves as NTC Vice-President for Conferences (2013-2014) and has been elected as NTC VP for Finance (2015-2016). He also co-founded the Oregon Chapter of the IEEE Education Society in 2005 and sits on its executive committee, and was Program Chair for the 1st and 2nd IEEE Conferences on Technology for Sustainability. His research activities are focused on electrically conductive adhesives, the electrical conduction mechanisms in discontinuous nanoparticle thin metal films, with applications to nanopackaging and single-electron transistor nanoelectronics, and on an NSF-funded project in undergraduate nanotechnology education. He has edited or co-authored five books on electronics packaging and two on nanodevices, (two of which have just been published in Chinese,) and lectures internationally on nanopackaging and electrically conductive adhesives.

\section{Dr. Jack C. Straton, Portland State University}

Jack C. Straton, Ph.D., is an Associate Professor at Portland State University, holding a joint appointment in Physics and in PSU's interdisciplinary University Studies Program, where his teaching focuses on diversity, science, and social responsibility. His research ranges from Nanometrology to Quantum Scattering Theory to Antiracist Pedagogy.

\section{Prof. Lisa H Weasel, Portland State University}

Lisa Weasel is an Associate Professor of Women, Gender \& Sexuality Studies at Portland State University. She has a PhD in molecular biology from Cambridge University (UK) and an undergraduate degree in biology from Harvard. She is the co-editor of the anthology Feminist Science Studies: A New Generation (Routledge 2001) and author of the book Food Fray: Inside the Controversy over Genetically Modified Food (Amacom 2009). She is currently Co-PI on a Nanotechnology Undergraduate Education (NUE) grant from the National Science Foundation. 


\title{
Nanotechnology Courses for General Education
}

\author{
James Morris ${ }^{1)}$, Peter Moeck' ${ }^{2)}$, Lisa Weasel ${ }^{3)}$, and Jack Straton²) \\ 1) Department of Electrical and Computer Engineering, \\ 2) Department of Physics, \\ 3) Departments of Biology and of Women, Gender, \& Sexuality Studies, \\ Portland State University, Oregon, USA
}

j.e.morris@ieee.org

\section{Abstract}

The goals of the program described below are to:

- Address the need for greater technical awareness in the general student population

- Extend the breadth of nanotechnology education for science and engineering majors, and

- Expose both student groups to the social, economic, and ethical issues of nanotechnologies.

This has been accomplished by three junior-level lecture courses and a senior/graduate laboratory that bring together technical and non-technical majors to jointly deal with a curriculum that includes both technical and social aspects of this rapidly developing field. The paper includes the objectives and structure of each course and results of the student and external evaluations where available.

Introduction

According to governmental policy documents ${ }^{1}, 6$ million "nanotech workers” will be needed to deal with new products worth approximately \$3 trillion/year in 2020. Compounding challenges to educating this prospective workforce arise from the fact that the field is by its very nature interdisciplinary ${ }^{2}$.

Nanotechnology must therefore play an essential role in the education and employment of our undergraduates, especially for the local high tech industry, which includes some of the leading companies engaged in nanotechnology R\&D, such as Hewlett-Packard, Intel, Xerox and Sharp. They are collectively by far the largest source of employment in the metropolitan area and in the state. To be successfully employed in the high tech industry, the student's education must be rigorous, integrating general education into science and engineering curricula.

We have developed a "sequence" of three 300-level General Education (GE) lecture courses in nanotechnology, based in the Departments of Physics, Biology, and Electrical \& Computer Engineering (ECE), which can be taken by majors for elective credit or by non-majors for GE credit $^{3,4}$. Ideally the new course sequence starts with PH382U Introduction to Nanoscience and Nanotechnology, followed by BI372U Nanotechnology, Society and Sustainability, and ECE383U Nanotechnology: Modeling \& Simulation, (where the "U" suffixes indicate GE eligibility,) but each course can stand alone. These courses are tailored to support interaction between STE (science, technology and engineering) and non-STE students, who will take them together. Two function as writing intensive courses (WIC), and there are no college-level prerequisites for any of them. There is also a supporting follow-on 2-credit Nanotechnology Laboratory course, (currently listed as ECE410/510.) 
General Education at this institution includes thematic "clusters" of junior courses. Students must choose three courses from one of these clusters which must be outside the student's major. The new courses PH382U, BI372U and ECE383U are all taught by active learning principles and are included in the junior Science \& Liberal Arts cluster as SCI382U, SCI372U and SCI383U, respectively, and in the Design Thinking/Innovation/Entrepreneurship cluster in the School of Business Administration.

Every graduate must complete the entire GE sequence ${ }^{5}$, which consists of:

- A freshman sequence of three quarters in a single elective cross-disciplinary topic

- Three elective sophomore courses which serve as prerequisites to three of the many junior GE clusters

- Three elective junior courses, (e.g. PH 382U, BI 372U and ECE 383U,) from a single cluster, (e.g. Science \& Liberal Arts or Design Thinking/Innovation/Entrepreneurship,) which includes courses from multiple departments, grouped around a single theme.

- An integrating two-quarter senior capstone experience, including some form of community service. (In engineering, this requirement is satisfied by the traditional capstone design project, performed in groups with participation and supervision by local industry. A future goal is the introduction of nanotechnology capstone projects which will integrate non-STE "graduates" of the nanotechnology courses into some of these industrial projects.)

The four goals for every GE course are:

- Inquiry and Critical Thinking: Students learn various modes of inquiry through interdisciplinary curricula-problem-posing, investigating, conceptualizing -in order to become active, self-motivated, and empowered learners.

- Communication: Students enhance their capacity to communicate in various wayswriting, graphics, numeracy, and other visual and oral means-to collaborate effectively with others in group work, and to be competent in appropriate communication technologies.

- The Diversity of Human Experience: Students enhance their appreciation for and understanding of the rich complexity of the human experience through the study of differences in ethnic and cultural perspectives, class, race, gender, sexual orientation, and ability.

- Ethics and Social Responsibility: Students expand their understanding of the impact and value of individuals and their choices on society, both intellectually and socially, through group projects and collaboration in learning communities.

These goals are demonstrated and regularly assessed for all GE courses and provide an ideal match to the non-technical sections (f, g, h, \& j) of the ABET (Accreditation Board for Engineering \& Technology) engineering program accreditation criterion three ${ }^{6,7}$. For many engineering students, the linkage of the UNST component of the degree structure to their technical studies will provide relevance and a more meaningful context ${ }^{8}$.

Furthermore, the introduction of these junior level courses will establish a Nano-Science and Engineering base for an interdisciplinary minor for the (technical) students who also choose designated advanced level courses in participating departments, and the new senior/graduate level inter-departmental laboratory course in the fabrication and characterization of nanomaterials and nanostructures (ECE410/510.) 
Examples of advanced level nanotechnology courses include:

- ECE 417/517 Nanoelectronics (4 credits): Operational principles and circuit applications of nanoelectronic devices: electron tunneling devices, (Esaki and resonant tunnel diodes, single electron transistors, nanodot arrays,) carbon nanotubes, nanowires, molecular electronics, and spintronics; nano-fabrication techniques.

- ECE 584/684 Nanotechnology \& Bio Sensors (4 credits): Overview of basic materials and methods in developing "lab-on-a-chip" based devices. Materials section involves an analysis of silicon-based devices, polymer based devices and nanomaterial based devices. Methods section covers the key features of micro fabrication, soft lithography, microfluidics, and nanofabrication. Applications section focuses on integration of micro and nanoscale structures for "lab-on-chip" devices.

- $\quad$ PH 481/581 Introduction to Nano(-Materials) Science and Engineering (4 credits): Nano-materials science and -engineering is portrayed as the ultimate interdisciplinary subject in the natural sciences and engineering disciplines. With this approach, PSU follows R.P.H. Chang's vision9: "Because disciplines are barely distinguishable at the nanoscale, the current boom in nano education offers us a unique opportunity to rebuild science education, literally from the bottom up, doing away with the classical disciplinary barriers that are rapidly becoming obsolete in our global research communities." and incorporate R. Roy's opinion ${ }^{10}$ : "Interdisciplinary Materials Research, historically speaking, is the turning point in the fragmentation - the fissiparous imperative - in the life of Western Science." Societal implications of Nanotechnology are also briefly discussed in this course. Coursework is partly based on the University's on-line nano-crystallography database ${ }^{11}$.

In addition, nanotechnology is steadily being integrated into existing courses across the campus, albeit primarily at the graduate level. Examples in ECE, for example, include:

- ECE 414/514 System integration \& packaging

- ECE 415/515 Introduction to semiconductor devices

- ECE 416/516 IC technologies

- ECE 529/629 Advanced VLSI CAD

Program objectives

There are many advanced, technical courses in Nanotechnology springing up in active research departments world-wide ${ }^{12}$, some with an interdisciplinary minor as anticipated here. This program adds a unique element, in that it addresses the recognized difficulties in developing technical awareness in the general population ${ }^{13-16}$ by bringing together technical and nontechnical majors in the same courses, with both technical and social contents.

The program objectives are stated as:

- To expand the educational opportunities in Nanoscale Science and Engineering (NSE) for STE majors, and especially to open up a greater level of awareness of the roles of the other disciplines.

- To increase awareness of the potential applications of NSE technologies, based on a qualitative understanding of their underlying scientific and engineering principles, amongst the general non-STE student body.

- To develop an understanding in both student groups of the social, economic, and ethical issues which are posed by the development and adoption of NSE technologies.

- To provide hands-on NSE laboratory experiences for both STE and non-STE students, and 
- To promote both broad and specialized NSE skills to enhance nanotechnology-related employment opportunities for STE and non-STE students alike.

These goals are achievable within the constraints of existing degree regulations and crowded curricula by using the existing campus junior GE elective structure.

The 50-60 STE majors who take the cluster courses annually (outside their majors) benefit in several ways:

- They see nanotechnology from a different technical disciplinary perspective, supplementing their advanced nanotechnology studies within the major,

- They gain an understanding of the social, economic, and ethical issues which surround their chosen area of specialization, and

- Their GE requirements are directly relevant to their major, providing context for greater interest.

Note that the remaining GE requirements provide more than enough room to complete institutional humanities and social science distribution requirements for the degree.

The non-STE majors explore the same social, economic, and ethical issues, but also develop an appreciation for the role of technology in society, and how scientists and engineers function, with nanotechnology examples providing a vehicle for this broader goal. This awareness must have some level of ripple effect, propagating into the general community. All students have some "hands-on" experience appropriate to each course, and more if they take the ECE lab course. Such experience with high-end equipment should especially benefit the non-technical students and provide them with a more concrete appreciation for these issues. The "hands-on" aspects of this program have extra impact on those students who learn better through activities rather than through lectures.

Local industry benefits by employing more broadly educated specialists and more technically aware non-specialists, and from the $\mathrm{R} \& \mathrm{D}$ efforts (including social impact studies) of the capstone teams. The reduced student set which can participate in nanotechnology capstone projects will be the most significant beneficiary group.

The academic community at large will have access to the course materials developed for the program, e.g. on NanoHUB, and undoubtedly a smaller proportion will take advantage of the on-line offerings which may be offered once the courses are established. (Most junior ECE courses are streamed on-line.).

Finally, the project team believes that the university itself will benefit from the program as a model for increased relevance of the GE sequence to students' majors in all specializations. This program will enable technical students to improve communication on technical issues with non-technical students. It will at the same time provide non-technical students with an appreciation for both the benefits and the possible problems inherent in developing these exciting new technologies.

These courses will be of special interest for teachers, (primarily for high school science teachers, but probably for a broader range, and including pre-service.) The original plan was to offer a composite university-credit summer course for teachers, but the local structure of continuing education for teachers has changed, and the current plan is to record a one-time workshop for future free streaming by interested parties. 
The program creates a nanotechnology curriculum that connects science and engineering students with other disciplines through the following objectives:

- The introduction of three new junior electives within the GE "clusters:”

o PH 382U (4 credits) Introduction to Nanoscience and Nanotechnology

- BI 372U (4 credits) Nanotechnology, Society, and Sustainability

o ECE 383U (4 credits) Nanotechnology: Simulation \& Design

Physics majors, for example, could take BI 372U and ECE 383U for two of their GE courses and $\mathrm{PH} 382 \mathrm{U}$ as an elective in the major, while all three courses would be available for GE credit for, say, History majors.

- These courses will form the foundation of the minor, when followed by more advanced specialized senior level courses, while simultaneously opening up the NSE experience to the broader student body.

- The development of the (cross-listed) laboratory course ECE 410/510 which will be pivotal to the interdisciplinary minor.

- The solicitation and development of industrially sponsored interdisciplinary "capstone" projects in nanotechnology, with the assistance of the stakeholder Advisory Board, which includes industrial representatives.

- The enhancement of nanotechnology employment opportunities for both STE and nonSTE graduates alike.

- The provision of regional, national and international access to all course materials developed.

- No pre-requisites beyond freshman admission requirements for any course (other than the sophomore GE prerequisites to the junior clusters, and senior/graduate standing for ECE 410/510.)

For the STE majors, there must be sufficient new engineering or scientific content in the junior courses to maintain their interest in the technical side, but the equally important objective is to engage them in the broader social issues to be raised and discussed. For the non-STE majors, the challenge is to present the technical material in a way which can be understood without the traditional background, so that the social issues can still be interpreted within a technical context. For some, those social controversies will be the place of emotional security and verbal strength from which they become willing to venture into the technical portion of the class. For example, both groups need to be aware of the difficulties of assessing social consequences in the micro-world of nanotechnology when it is not clear what this world is like. This potentially transformative model will demonstrate both the synergy and the practicality of involving both technical and non-technical students to better explore new technical concepts, their promise, and their possible costs/dangers.

In short, the program brings together STE and non-STE majors in the same courses, which will form the foundation of a NSE minor. These diverse students will jointly deal with a curriculum that includes both technical and social aspects of this rapidly developing field. For some, this will also provide preparation for their Senior Capstone projects, which are likewise collaborative across disciplines. After completion of a course, both sets of students will be aware of possible benefits of nanotechnology as well as possible problems. As examples, selfassembly may lead to reduced cost and therefore widespread use of new technologies, while the escalating use of silver nanoparticles in health, electronics, and the home, for example, may be affecting the aqueous environment and food chain ${ }^{17}$. Nanostructures are components of various composite materials with such useful functions as increased strength and stain resistant 
coatings, but toxicity of nanoparticles is poorly understood and clearly different from that of bulk material of the same composition. This furthers our goal of creating better informed and more engaged citizens.

A term-by-term course schedule is shown in Table 1.

\begin{tabular}{|c|c|c|c|c|c|c|c|c|c|c|}
\hline 2013 & \multicolumn{4}{|c|}{2014} & \multicolumn{4}{c|}{2015} & \multicolumn{2}{c|}{2016} \\
\hline Fall & Winter & Spring & Summ & Fall & Winter & Spring & Summ & Fall & Winter & Spring \\
\hline ECE383 & BI372 & PH382 & & PH382 & BI372 & ECE383 & Wkshp & PH382* & BI372* & ECE383 \\
\hline & & & & & Lab & & & Lab & & \\
\hline
\end{tabular}

Table 1. Past and planned course schedule. (*Possibly adjunct-taught)

Program evaluation

The Research Group at University of California Berkeley's Lawrence Hall of Science is contracted to evaluate the impact and merit of the program by examining the quality and effectiveness of its project deliverables and the implementation of these deliverables for its primary audiences. The evaluation employs a variety of instruments and approaches at various phases of the project to determine the extent to which the project deliverables foster a deeper understanding of the applications of nanotechnology as well as the social, economic and moral issues surrounding the field, and provide hands-on lab experiences and enhance awareness of and preparedness for careers in nanotechnology. Primary sources of data include written surveys administered on-line to students using a pre/post methodology such that changes in knowledge, awareness and attitudes can be documented. The evaluation examines how the program impacts all students taking the courses, both STE and non-STE. Research Group staff have designed surveys, observation instruments and interview protocols to collect data on how students perceive and understand nanotechnology content and issues, and how their knowledge of, interest in and attitudes toward related content and issues are impacted by their participation in the program. Formative evaluations are being conducted as the courses are being developed and tested to determine the extent to which the program goals of are being met. Findings from these formative processes are fed back into the project during its development and implementation to ensure high quality and effective programs. In addition, summative evaluation is being conducted to determine the overall impact of the completed program on participants. Data are analyzed through both qualitative and quantitative methods using descriptive and comparative analyses to answer the evaluation questions, to identify patterns, determine relationships between variables and highlight trends. Prior to analysis, emergent coding is used to generate categories for open-ended responses; for pre/post methodologies, paired sample t-tests will be utilized to examine changes in responses over time.

The summative evaluation is designed to examine the extent to which the program meets its goals of:

- Expanding the educational opportunities in NSE,

- Providing hands-on NSE laboratory experiences for students,

- Promoting broad and specialized NSE skills to enhance nanotechnology-related employment opportunities,

- Increasing student awareness of the potential applications of NSE technologies, and

- Increasing student understanding of the social, economic, and ethical issues which are posed by the development and adoption of NSE technologies.

Data are collected through written surveys, individual interviews (by Skype) and group observations. Research Group staff conduct de-briefing meetings with project faculty after completion of each evaluation activity. Written reports are prepared upon completion of major 
evaluation studies, including a description of the subject pool, data collection protocols, analysis methods and findings, and conclusions/ recommendations based on findings.

At the time of paper preparation, the evaluation program has been hampered by personnel changes and by administrative delays, e.g. for Institutional Review Board approvals, but some early results have previously been reported ${ }^{4}$.

PH 382/SCI 382U: Brief description of the course and its objectives

This course gives an introduction to nanoscience and nanotechnology (nanotech). Structure property/function relationships at the nanometer length scale are identified as the core concepts of nanoscience. The corresponding synthesis and processing steps, and the performance of such materials under environmental constraints, constitute the core of nanoengineering. Both inorganic and biological materials are considered. Nanoscience is presented as the convergence of applied physics, applied chemistry, and molecular biology focusing on phenomena and opportunities to fabricate at the nanometer scale where the energy scales of a variety of processes conflate ${ }^{18}$. As nanotech is the epitome of interdisciplinarity, the course attempts to build up student's communication skills and attempts to get them into the habit of life-long learning.

Another goal of the course is the aiding of the realization in the students' minds of the importance of mathematics in the natural sciences. As atomic-level relations between structures and physical/chemical properties are at the core of materials science, an introduction to basic crystallography is part of our course. This is because (i) most technologically important inorganic materials are crystalline, (ii) most properties of crystals are anisotropic, (iii) crystallography has been generalized ${ }^{19-23}$ to the comprehensive science of structures, properties and functions of all forms of condensed matter at the atomic and mesoscopic length scales, and (iv) it allows the instructor to introduce simple but very powerful mathematical concepts.

These concepts are the Bravais lattices on which Miller indices are defined and point symmetries that need to be combined with translation symmetries in order to arrive at the space symmetries that crystals can be classified into. Although full mastery of this mathematical framework is not expected from the students, they should ideally gain an appreciation that it is only by abstract mathematics that the atomic structures of crystalline materials becomes comprehensible.

Note that generalized crystallography ${ }^{19-23}$, i.e. "the science of structures at a particular level of organization, being concerned with structures bigger than those represented by simple atoms but smaller than those of, for example, the bacteriophage"20, actually forms the "structural foundations" of nanoscience and nanotechnology, so it must be one of the foundations of our course. Our course only mentions progress in the elucidation and application of non-crystalline and liquid structures ${ }^{20-23}$ briefly, but demonstrates structures and functions of physiological important proteins with the help of the interactive Proteopedia web site ${ }^{24}$.

The distinction between qualitative and quantitative physics is made so that students understand that we build things using quantitative models while we typically envision things qualitatively. The learning objectives are: 
- Appreciation of the differences between classical physics and quantum physics, general chemistry and physical chemistry, general biology and physical biology (biophysics);

- Appreciation of how science and technology at the nanometer length scale differ from traditional science and technology at larger length scales;

- Appreciation of the convergence of all natural sciences at the nanometer length scale;

- Appreciation that this convergence offers unprecedented opportunities of nanoengineering resulting in nanotechnologies;

- Appreciation of the effects of nanoscience and nanotechnology on society and students' future personal life.

\section{PH 382/SCI 382U: Philosophy and structure of the course}

This general science education course at the 300 level (which requires no prerequisites other than junior standing) covers an eclectic mix of phenomena at the one to approximately $100 \mathrm{~nm}$ length scales (i.e. nanoscience) and their contemporary technical exploitation (i.e. nanotechnology) in a fairly qualitative manner. Nanotechnology is in this course understood and taught as "the buzzword and an umbrella term to designate nothing less than the state of the art in science and technology in what is the normal progression and evolution of the relationship of humankind with its habitat and environment ${ }^{25}$." We also contrast this definition with the well known definition of the field as provided by the National Science Foundation ${ }^{26}$ in the year 2000. This contrasting leads to a refinement in the minds of the students of what the course is all about.

Since there is by necessity an eclectic mix of phenomena to be covered during the course, a philosophy that holds it all together is all the more important. This philosophy is described in considerable detail in ref. ${ }^{27}$. French philosopher Gaston Bachelard's technoscience concept ${ }^{28}$ is used as a guiding principle in delivering the course material and for the course philosophy. This means that in addition to a mix of small length scale science and engineering concepts, our 300 level course covers also their wider technological and social context. The technoscience concept recognizes that scientific knowledge is not only socially coded and historically situated, but also sustained and made durable by utilized classes of materials ${ }^{29}$.

Important for making progress while applying the technoscience approach in class is the overcoming of epistemological obstacles (Bachelard's obstacle épistémologique). Such obstacles which need to be dealt with in class are popular and pseudo-scientific preconceptions about nanotechnology that are initially held by many students of our course. As an example of a popular misconception and how we remove that obstacle to further learning, we will discuss in a separate paper what is wrong with the popular culture perception of allegedly perpetual progress in information technologies and consumer electronics (Moore’s law).

We argued in ref. ${ }^{27}$ that materials science and engineering ${ }^{30}$ is the foundation of nanoscience and nanotechnology in the widest possible sense. The scaling down of the size of transistors in integrated circuits that Moore's law allegedly describes was for example only possible by progress in the double discipline materials science and engineering ${ }^{31}$. As already mentioned above, our course gives also a brief introduction to geometric structural crystallography as part of an introduction to this double discipline. This introduction is supported by 3D printed model structures, which are outcomes of a collaboration $27,32-35$ between the instructor and a former student of the advanced undergraduates/graduates version of this course (i.e. the above mentioned PH 481/581 Introduction to Nano(-Materials) Science and Engineering). 


\section{BI 372/SCI 372U: Course objectives}

This course introduces students to ethical, legal and social issues associated with nanotechnology. Particular emphasis is placed on understanding the implications of nanotechnology for the environment and human health, in both local and global contexts. Contributions and concerns pertaining to nanotechnology's impact on the economic, environmental, and social aspects of sustainability are also addressed. Students develop critical analysis and communication skills for approaching controversies pertaining to nanotechnology and society.

The emergence of any new technology often raises the challenge of balancing risks and benefits, and in this regard nanotechnology is no exception. Class subject matter and format will examine the implications of nanotechnology within a socioeconomic-environmental context. Nanotechnology has broad social, ethical and legal implications ranging from environmental remediation and/or contamination to social justice and equity applications in developing countries, to biomedical treatments and interventions, to intellectual property dilemmas. Students gain familiarity with these applications as well as skills in analyzing and balancing risks and benefits.

The course exposes students to expert views from a variety of perspectives and will help students develop critical analysis and reasoning skills working both individually and collaboratively. Emphasis is placed on integrating technological literacy with critical inquiry and problem solving in social and ethical context.

\section{BI 372/SCI 372U: Course structure}

A lecture-by-lecture course plan is presented in Table 2 with the grading schedule in Table 3.

\begin{tabular}{|l|l|l|l|}
\hline Week & Topic & Reading & Assignment/In-class \\
\hline 1 & Intro to course & $\begin{array}{l}\text { WIN Ch 1 } \\
\text { Context of nanotechnology? } \\
\text { Scheufele \& Lewenstein, } \\
\text { Public and Nanotechnology } \\
\text { controversies }\end{array}$ & \\
\hline 2 & What is nanotech? & $\begin{array}{l}\text { Feynman, Plenty of } \\
\text { room at the bottom; } \\
\text { Toumey, Plenty of room, } \\
\text { plenty of history }\end{array}$ & \\
\hline 3 & Nanotech origins 1 & WIN Ch 3 & You Tube review due \\
\hline & Environmental considerations & $\begin{array}{l}\text { NGS Ch 3 Ch 2 } \\
\text { Diallo \& Brinker, } \\
\text { Nanotechnology for } \\
\text { Sustainability }\end{array}$ & \\
\hline 4 & $\begin{array}{l}\text { Environmental considerations: } \\
\text { environmental remediation }\end{array}$ & Guest speaker & \\
\hline & Environmental considerations & WIN Ch 8 & $\begin{array}{l}\text { In class nano- } \\
\text { environmental project }\end{array}$ \\
\hline 5 & Food and Agriculture & $\begin{array}{l}\text { NGS Ch 5 } \\
\text { Nano4Food readings } \\
\text { Project DUE }\end{array}$ & \\
\hline & Human Health: Personal & WIN Chs 11, 12 & \\
\hline
\end{tabular}




\begin{tabular}{|l|l|l|l|}
\hline 6 & Human Health: Global & NGS Ch 7 & $\begin{array}{l}\text { In class nano health } \\
\text { project }\end{array}$ \\
\hline & In-class writing workshop & & $\begin{array}{l}\text { Nano Health project due. } \\
\text { YouTube draft proposal } \\
\text { due }\end{array}$ \\
\hline 7 & $\begin{array}{l}\text { Ethics and Justice: Distributive } \\
\text { Justice }\end{array}$ & WIN Ch 7 & YouTube proposal due \\
\hline 8 & $\begin{array}{l}\text { Ethics and Justice: } \\
\text { Global South }\end{array}$ & NGS Chs 6, 8 & \\
\hline 9 & Regulation/Policy & WIN Chs 5, 6 & \\
\hline & Regulation/Policy & NGS Chs 11, 12 & \\
\hline 10 & Film: The Singularity is Near & & $\begin{array}{l}\text { Prey reading completed; } \\
\text { review due }\end{array}$ \\
\hline & $\begin{array}{l}\text { Cook discussion: Prey } \\
\text { prep for exam }\end{array}$ & & \\
\hline FINAL & \begin{tabular}{l} 
YouTube film fest \\
\hline
\end{tabular} & & $\begin{array}{l}\text { Scoring sheets; } \\
\text { YouTube final project due }\end{array}$ \\
\hline
\end{tabular}

Notes:

(WIN) What is Nanotechnology and Why Does it Matter? From Science to Ethics, Allhoff, Lin \& Moore, Wiley 2010. (Required textbook)

(NGS) Nanotechnology and Global Sustainability, Maclurcan \& Radywyl, CRC Press, 2011. (Required textbook)

Table 2. Course outline for BI/SCI 372

\begin{tabular}{|c|c|}
\hline YouTube review: & $10 \%$ \\
\hline \multicolumn{2}{|c|}{$\begin{array}{l}\text { Find 3-4 short clips on nanotechnology on YouTube and analyze the ways nanotechnology is } \\
\text { represented: the science, technology, \& implications, in social, ethical, health, and environmental } \\
\text { contexts. ( } 3-5 \mathrm{pp} \text { ) }\end{array}$} \\
\hline YouTube script: & $10 \%$ \\
\hline \multicolumn{2}{|c|}{$\begin{array}{l}\text { Write a proposal for a YouTube video on nanotechnology, outlining the script, the imagery and } \\
\text { dialogue, including both science/technology and social/ethical/environmental issues. }\end{array}$} \\
\hline YouTube project: & $20 \%$ \\
\hline \multicolumn{2}{|c|}{$\begin{array}{l}\text { Translate your script into actual video based on feedback on your proposal. (Any quality level from } \\
\text { phone to professional is acceptable.) }\end{array}$} \\
\hline You Tube project reviews: & $10 \%$ \\
\hline \multicolumn{2}{|c|}{ Screen your YouTube video for the class. Evaluate all videos (based on a scoring sheet provided.) } \\
\hline Environmental project: & $15 \%$ \\
\hline \multicolumn{2}{|c|}{$\begin{array}{l}\text { 3-5pp paper: Risks and Benefits of Nanotechnology for the Environment based on a peer-reviewed } \\
\text { article with quantitative data on nanotechnology in the environment }\end{array}$} \\
\hline Health project: & $15 \%$ \\
\hline \multicolumn{2}{|c|}{$\begin{array}{l}\text { 3-5pp paper: Risks and Benefits of Nanotechnology for Health based on a peer-reviewed article with } \\
\text { quantitative data on an application of nanotechnology to human (and/or animal) health }\end{array}$} \\
\hline Review of "Prey” by Michael Chrichton & $10 \%$ \\
\hline \multicolumn{2}{|c|}{ 4-6 pp. review evaluating nanotechnology in this fictional work } \\
\hline Class participation and group work & $10 \%$ \\
\hline
\end{tabular}

Table 3. BI/SCI 372 grading scheme.

The YouTube projects are the culminating feature of the course and are presented in an impressive final course meeting. Two of the shorter examples (by Maria Cassera and Jason Churn) have been shown publicly ${ }^{36}$. 


\section{BI 372/SCI 372U: Course observations}

Teaching STE and non-STE majors simultaneously in the same classroom can be a challenge. At one end of the spectrum are students who may have heard little or nothing about nanotechnology, or may feel fear or intimidation when considering its applications. At the other end are students who may not just be familiar with nanotechnology, but may be engaged in its pursuit and may not be interested in or open to considering the social ramifications and acceptance of what they consider a single-minded scientific pursuit. Of course, the real life classroom contains students everywhere along this spectrum, most of whom are eager or at least interested in learning more about nanotechnology and its implications for their future lives and careers.

The BI 372U course, Nanotechnology, Society and Sustainability has been made up of a disproportionate number of STE students versus those in non-STE majors, in an approximately 2:1 ratio heavily favoring Biology majors. In addressing the various needs and abilities of students in the class, several learning activities have been particularly successful in engaging different groups of students and harnessing their ability to learn from one another.

The first of these is the research paper meet'n'greet activity. This format is used four times during the quarter, focusing on nanotechnology applications pertaining to the environment; health; food and agriculture; and consumer products. Students are instructed in how to use research article databases, given an initial peer-reviewed research article selected by the instructor to read as homework and analyze in class, and assigned to obtain their own peerreviewed article on an application of nanotechnology to the relevant topic. A homework worksheet is used as a guide to help students identify the key elements of the paper. Students then bring a copy of their paper and the homework worksheet to class, and engage in short, 1:1 meetings with classmates (approximately 8 minutes per pair) during which time they explain their paper to their partner, with the opportunity to collaboratively work out any questions they have about the data or the research. This enables non-STE students to harness the expertise of the STE majors, while those with stronger techno-scientific backgrounds are challenged to explain their papers in layperson's terms to a non-major audience. Students exchange pairs approximately 5 times, and then the class is surveyed for superlatives- "the most important finding," "the most unexpected application," "the application likely to impact the most people," etc. In practice, this generates an extremely wide range of applications of nanotechnology, and by repeatedly explaining their paper to others, students gain confidence and familiarity with the research, regardless of their background.

This exercise is followed during a subsequent class session in which students work in groups of 6 on a policy roundtable. For homework prior to the class meeting, students are assigned a white paper (or other relevant, wide-ranging background) to read addressing policy implications of nanotechnology applications in areas of environment, health, food and agriculture, and consumer products (one topic per class meeting). The groups, (mixed with regard to STE backgrounds,) meet in class and are asked to identify the top two areas of nanotechnology within that field (environment, health, food and agriculture, and consumer products) to support, and the top two risk areas that need investigation. Groups are instructed to find consensus on their choices, and to provide significant justification for those choices. This leads to a lively and robust atmosphere as students lobby for what they consider most important. The consensus process means that while specific examples are requested, students necessarily need to expand their individual focus to find common ground with group members. While some groups have difficulty coming to consensus and as a result, articulate less specific 
foci, even these groups benefit from the opportunity to discuss in detail and examine evidence for various applications and risks. The large majority of student groups come to well-argued consensus, and when the whole class is brought back together, often a larger class-level consensus emerges on big-picture priorities (such as point-of-use energy generation and water purification as environmental applications; and sensors and reclamation as risks, for the environment topic day).

These two types of activity are repeated for each nanotechnology area addressed in class (environment, health, food and agriculture, and consumer products) and as students gain familiarity with the format, their participation increases and becomes more detailed. These activities set the stage for greater comfort across the STE/non-STE divide, and enable both groups of students to claim expertise and practice communication and argumentation skills with the nanotechnology research and policy literature. These modules can be integrated into and lead to a variety of subsequent class activities and structures, from serving as the basis for research papers to the development of educational videos to writing product proposals. In the BI 372U course, we find that once the stage is set for comfortable, constructive communication across the STE/non-STE divide, students in both groups learn better and experience positive course outcomes.

\section{ECE 383/SCI 383U: Course objectives}

Engineers use modeling and simulation software all the time for both design and analysis. This course provides insight into the engineering design process for non-engineers and exposure for engineering students to a new suite of modeling tools. These are used to model nanotechnology phenomena, materials, structures, and devices, and to design applications. The course draws extensively upon the resources of the NSF- supported Purdue website repository "NanoHUB," but students also develop and run their own models using free software (LT-SPICE.) The class runs in an active learning mode in a lecture/lab environment that pairs STE majors with nonSTE majors. Most of the non-STE students have never taken calculus, which is therefore not used.

The Course Outcomes are stated to be:

- Understanding of the basic concepts of nanotechnology

- Understanding of the role of computer simulation in engineering design

- Competence in the application of one simulation software

- Understanding of the physical operation of selected nanodevices

- Understanding of environmental, health and social issues of nanotechnology

- Ability to write competently and appropriately to the context

This ECE course develops an appreciation of the potential applications of nanoscale active devices and systems, with electron tunneling as the mechanism in focus. The challenge is to provide material accessible to students with no calculus or physics background, while offering appropriate challenge to ECE and physics majors. The course also provides non-technical majors with some more general appreciation of how device principles can be employed in circuit and sensor applications. The GE faculty experience is that the most successful GE courses are often those where the instructor presents personally interesting material or viewpoints which would not normally find their way into the majors' courses. Following this thought, the current plan is to use nano-devices such as TDs, RTDs, SETs, etc., as vehicles to show STE and non-STE students alike how ECE designers work, with an emphasis on 
graphical techniques and graphics-based simulations. Ad hoc guest lecturers also present research related material, e.g. nano-laboratory safety issues, etc.

\section{ECE 383/SCI 383U: Course structure}

Catalog description: Introduction to basic electrical concepts, nanotechnology, and the principles of modeling and simulation. Modeling and simulation are used to examine environmental and health hazards and the applications of nanotechnology in environmental and biomedical sensing and in current and future nanoelectronic technologies. Course is designed for both STE and non-STE majors.

This course provides insight into the engineering design process for non-engineers and an introduction to the applications of nanotechnology in micro/nanoelectronics, environmental nanosensors, biomedical devices, etc. Understanding of these applications is achieved by the combination of qualitative explanations of device operation with quantitative simulations of performance. The initial course plan is shown in Table 4.

\begin{tabular}{|l|l|}
\hline Lectures & Simulation Labs \\
\hline Syllabus \& Introduction to EE concepts & Introduction to EE concepts (cont'd) \\
\hline Nanoparticles & 1. Introduction to LT-SPICE \\
\hline Electron tunneling & 2. Coulomb blockade \\
\hline Carbon Nanotubes (CNTs) & 3. Quantum Cellular Automata (QCA) \\
\hline Resonant Tunnel Diode (RTD) & 4. CNT composites \\
\hline NanoCMOS (NanoHUB) & 5. RTD \& circuits \\
\hline Single Electron Transistor (SET) & 6. SET \& circuits \\
\hline Memristor & 7. Memristor \& circuits \\
\hline Nanosensors & 8. Nanosensors; \\
\hline Environment; Life Cycle Analysis (LCA) & Environmental/social discussion \\
\hline \multicolumn{2}{|c|}{ Table 4. ECE/SCI 383 course outline } \\
\hline
\end{tabular}

An undergraduate peer mentor who took the class in fall 2013 will work with students in the SPICE lab sessions in spring 2015. The course will use peer mentors on an on-going basis rather than graduate teaching assistants.

The BSEE and BSCpE curricula are very full and with a specialization track structure, students have a very limited choice of ECE electives which must be selected from chosen track's range. The program's concept requires a balance of STE and non-STE students to fulfill its objectives and the challenge is to attract enough ECE students to provide a STE core. The WIC designation might provide added motivation for ECE students to take the course, because the Department decided to accept it in lieu of the traditional Technical Writing class. However, given that half of the ECE juniors are community college transfers who have generally satisfied their writing requirements at the lower division, and assuming that the remainder's writing courses will be distributed uniformly across three quarters, it needs almost all of the eligible ECE majors to take the nanotechnology course to fill the STE slots and balance the non-STE students. An English Department graduate student functions as a WIC tutor with the same guidelines as in other WIC classes across campus, i.e. a 3-step process for submission and grading of all assignments. 
The lab reports and weekly discussions provide the source material for the writing assignments which include examples of: Technical report, Executive summary, Journal/conference paper, newspaper article, position paper, e-mail, Powerpoint ${ }^{\mathrm{TM}}$, etc.

\section{ECE 383/SCI 383U: Course modifications}

The course has only run once, and there were no pre-post surveys or other forms of external evaluation performed. However, the campus administers its own internal student course evaluations, and these and conversations with students during the course provided more than enough information to point to needed changes.

The main point was that while students in BI $372 \mathrm{U}$ expressed a desire for more technical content, the reverse was true for ECE 383U, where the pace of technical information transfer could be described as frenetic, even with no calculus employed. In addition, while students expressed appreciation for the required textbook ${ }^{37}$ and the prescribed reading schedule, the subsequent discussion promised in the syllabus generally gave way to the "need" to get through more theory to support the labs. Furthermore, the "lab" session was originally scheduled for sufficient time for students to be assisted in starting their SPICE simulations, with the expectation that they would complete them independently at home. That worked for some, but in general it was clear that more lab time is needed to move others further along.

Instead of two 110-minute classes, one intended as lecture/discussion and the other for the SPICE laboratory, there will be in future:

- One 75-minute lecture (streamed on-line if possible)

- One 75-minute discussion period

- One 170-minute lab period

These times meet the normal campus distributions for a $3+1$ credit course. In addition, a block of time is scheduled for individual meetings with the WIC tutor.

But the biggest changes required are modifications to the SPICE assignments themselves. The design of the experiments leant heavily on the research literature, and frankly some of the models could not possibly have worked as published. While some changes will be minor, others are best described as "back to the drawing board."

One aspect of the course which did work extremely well was the interaction between the STE and non-STE students, although mainly one way in SPICE lab assistance, possibly because there was less discussion than intended on social issues, and therefore less need for the nonSTE viewpoint. Also, there was no evidence of any disparity in the writing abilities of the STE and non-STE students.

\section{ECE 410/510: Course objectives}

The laboratory course is focused on the preparation and properties of metallic nanoparticles, especially in the form of discontinuous metal thin films (DMTFs) ${ }^{38-40}$, with the Course Outcomes:

- Experience in vacuum technology

- Experience in thin film deposition and nanoprocessing

- Experience in the electrical, thermal and optical characterization of nanomaterials

- Experience in TEM, SEM and AFM characterizations of nanomaterials

- Familiarity with nanoparticles and CNTs 
- Experience in effective laboratory report writing

ECE 410/510: Course structure

The experimental sequence is listed in Table 5. Most of experiments are done asynchronously, but the first is preparatory for the following experiments 2 to 4 , and the first two for experiments 3 to 6, so all groups are scheduled to do Experiment 1 at various times through the first week, and Experiment 2 also on an accelerated schedule.

\begin{tabular}{|ll|}
\hline 1. & Deposition of discontinuous metal thin film (DMTF) \\
\hline 2. & Deposit DMTF contacts (Hummer) \\
\hline 3. & TEM examination of DMTF (\& Debye-Scherrer) \\
\hline 4. & DMTF optical properties \\
\hline 5. & AFM examination of DMTF (\& deposition thickness calibration) \\
\hline 6. & DMTF electrical properties (thermal and voltage) \\
\hline 7. & Nano-sintering and SEM exam \\
\hline 8. & CNT percolation with SEM exam of CNT arrays \\
\hline
\end{tabular}

Table 5. ECE 410/510 experimental sequence

The course ran for the first time in winter 2015, with the assistance of a graduate student as a "mentor." Next time, he will probably accept more responsibility for the course as a Teaching Assistant, with the aid of an Undergraduate Mentor.

Also in the future, more experiments might be added to provide more choice, but the laboratory space is already at capacity. Although undecided at this time, a project might be added to the experiment list above, partly to justify the 2-credit weighting which exceeds the ECE norm but combines with other related science labs that students might wish to take too. In addition, campus policy requires some experiential difference to distinguish the graduate from the senior expectations in a 400/500-level course. This would argue for a supplementary graduate project, but there are no graduate students currently enrolled.

There have been some start-up equipment teething problems, especially with building the vacuum deposition system from recycled components and bringing it up to reliable operation on schedule. The Hummer referred to in Table 5 has not yet been repaired and contact depositions are being done in the DMTF deposition system. There are more ongoing minor issues, but nothing insurmountable.

\section{Summary and conclusions}

A nanotechnology program has been developed to serve both as STE major electives and nonSTE GE courses. To meet that second objective, no courses have any pre-requisites beyond those for freshman entry. There is also a senior/graduate-level nanotechnology lab course which offers hands-on experience in the field, especially with nanoparticles.

So far, BI 372U and PH 382U have been blessed with maximum enrolments. By contrast, both ECE courses have both had enrolments well below the nominal minimum to run, but the department elected to offer them anyway to facilitate the development process. 
The objectives and teaching concept for the junior GE courses all target a 1:1 STE/non-STE mix for maximum efficiency in groups of two, but probably could survive 1:2 and groups of three. Even 1:2 has not actually been achieved in any class yet, with BI 372U and PH 382U being dominated by biology and physics majors respectively. Possibly the lack of ECE students able to take ECE 383U might yield the target balance, but at the expense of overall numbers.

\section{Acknowledgements}

These courses are being developed with the support of NSF Grant EEC-1242197 under the Nanotechnology Undergraduate Education program and will all be externally evaluated for quality feedback. Dr. Trevor Snyder of 3D Systems Corporation is thanked for the 3D printing of crystallographic models for PH $382 \mathrm{U}$.

References

1. Mihail C. Roco, Chad A. Mirkin and. Mark C. Hersam, Nanotechnology Research Directions for Societal Needs in 2020, Springer, 2011.

2. Michael L. Grieneisen1 and Minghua Zhang, "Nanoscience and Nanotechnology: Evolving Definitions and Growing Footprint on the Scientific Landscape,” Small, 7(20), pp. 2836-2839, October 17, 2011.

3. J. Morris, L. Weasel, and P. Moeck, Comprehensive undergraduate nanotechnology education at Portland State University, Proc. 2013 National Educators Workshop, Materials in Enabling Technologies: Defining the Future, November 3-5, 2013, Tulsa, OK

4. James Morris, Lisa Weasel, Peter Moeck and Juna Snow, (2014). Nanotechnology Courses for General Education (Plenary Paper). Proc. 7th International Spring Seminar on Electronics Technology (ISSE), May 2014, Dresden, Germany.

5. White, Charles R., "A Model for Comprehensive Reform in General Education: Portland State University," The J. of General Education, 43 (3), 1994, pp. 168-237.

6. Russell L. Pimmel,, "Student learning of Criterion 3 (a)-(k) Outcomes with Short Instructional Modules and the Relationship to Bloom’s Taxonomy,” J. Engineering Education, 92 (4), 2003, pp. 351-359.

7. Larry J. Shuman, Mary Besterfield-Sacre, and Jack McGourty, “The ABET "Professional Skills” - Can They Be Taught? Can They Be Assessed?” J. Engineering Education, 92 (4), 2003, pp. 351-359.

8. Matthew J. Drake, Paul M. Griffin, Robert Kirkman, and Julie L. Swann, "Engineering Ethical Curricula: Assessment and Comparison of Two Approaches,” J. Engineering Education, 94 (2), 2005, pp. 223-231.

9. $\quad$ R. P. H. Chang, “A call for nanoscience education,” Nanotoday, 1(2) May 2006, pp. 6-7.

10. R. Roy, “Interdisciplinary Materials Research: The Reluctant Reformer of Western Science”, IUMRS Facets , 4 (2005) pp. 18-21 (ISSN 1537-1664)

11. Moeck, P. et al., "Crystal structure visualizations in three dimensions with support from the open access Nano-Crystallography Database”, J. Mater. Educ. 2006, 28(1-2), 87-95.

12. Marc C. Hersam, Melissa Luna, and Gregory Light, "Implementation of Interdisciplinary Group Learning and Peer Assessment in a Nanotechnology Engineering Course,” J. Engineering Education, 93(1), 2004, pp. 49-57.

13. D. A. Scheufele1and B. V. Lewenstein, "The public and nanotechnology: How citizens make sense of emerging technologies,” Journal of Nanoparticle Research, 7 (2005) pp. 659-667.

14. M. C. Roco, "Broader societal issues of nanotechnology," J. Nanoparticle Res. 5 (3-4) (2003) pp. 181189

15. P. Goodhew, "Education moves to a new scale,” Nanotoday, 2006, 1(2), pp. 40-43

16. A. M. Waldron, "Nanotechnology in public," Nanotoday, 2006, 1(2), p. 56

17. S. N. Luoma, "Silver Nanotechnologies and the Environment: Old Problems or New Challenges” Project on Emerging Nanotechnologies PEN 15, Sept 2008, (PEW Charitable Trusts \& Woodrow Wilson International Center for Scholars)

18. R. Phillips and S. R. Quake, “The Biological Frontier of Physics,” Physics Today, May 2006, pp. 38-43.

19. J. D. Bernal and C. H. Carlisle, Soviet Phys. Crystallogr. 13, 811 (1969).

20. A. Mackay, Izvj. Jugosl. centr. krist. (Zagreb) 10, 15 (1975).

21. N. D. Mermin, Rev. Mod. Phys., 64, 3 (1992).

22. A. L. Mackay, J. Molecular Structure (Theochem) 336, 293 (1995). 
23. J. L. Finley, Fundamentals of Physics III - Structure of Solids and Liquids: Crystallography, Encyclopedia of Life Support Systems, 2009; http://www.eolss.net/

24. http://www.proteopedia.org/wiki/index.php/Main_Page,

J. Prilusky, E. Hodis, D. Canner, W.A. Decatur, K. Oberholser, E. Martz, A. Berchanski, M. Harel and

J. L. Sussman, J. Struct. Biol. 175, 244 (2011).

25. D. Jost, NCRR trade regulations, Swiss national center of competence in research, working paper no. 2009/21, May 2009.

26. http://www.nsf.gov/crssprgm/nano/reports/omb_nifty50.jsp

27. P. Moeck, J. Stone-Sundberg, T. J. Snyder, and W. Kaminsky, "Enlivening a 300 level general education class on nanoscience and nanotechnology with 3D printed crystallographic models," J. Mater. Edu. $\underline{\mathbf{3 6}}$ (2014) 77-96

28. G. Bachelard, La materialisme rationnel, Presses Universitaires de France, Paris, 1953, ISBN 2-13056285-X;

http://classiques.uqac.ca/classiques/bachelard_gaston/materialisme_rationnel/materialisme_rationnel.pd $\mathrm{f}$

29. http://en.wikipedia.org/wiki/Technoscience

30. R. W. Cahn, The Coming of Materials Science, Pergamon, 2002.

31. C. W. Liu, M. Östling, and J. B. Hannon, "New materials for post-Si computing", MRS Bulletin 39, 658 (2014).

32. P. Moeck, J. Stone-Sundberg, T. J. Snyder, and W. Kaminsky, Open Access Resources for Crystallography Education in Interdisciplinary College Courses: Crystallographic Databases and 3D Printed Models, MRS Online Proceedings Library 1716 (2014) mrss14-1716-fff03-09; doi:10.1557/opl.2014.872

33. P. Moeck, W. Kaminsky, and T. Snyder, "3D printing of crystallographic models for interdisciplinary college education,” Acta Cryst. A70 (2014) C1379, http://asp-us.secure-

zone.net/v2/index.jsp?id=144/235/1343\&startPage=1391

34. W. Kaminsky, T. Snyder, and P. Moeck, "3D printing of crystallographic models and open access databases,” Acta Cryst. A70 (2014) C1278, http://asp-us.secure-zone.net/v2/index.jsp?id=144/235/1343\&startPage=1290

35. D. J. Stone-Sundberg, T. Snyder, W. Kaminsky, and P. Moeck, "3D printed models of small and large molecules, structures and morphologies of crystals as well as their anisotropic physical properties", Cryst. Res. Technol. (2015) first published online: 5 MAR 2015 | DOI: 10.1002/crat.201400469

36. Nanoscale Science and Engineering Education Workshop, December 11-12, 2014, Westin Arlington Gateway Hotel.

37. Mel I. Mendelson, “Learning Bio-Micro-Nanotechnology,” CRC Press (2013), ISBN: 978-1-42008203-6

38. J. E. Morris and T. J. Coutts, "Electrical conduction in discontinuous metal films; a discussion," Thin Solid Films 47, p. 3-65 (1977). [invited review]

39. F. Wu and J. E. Morris, "Modeling conduction in asymmetrical discontinuous thin metal films" Thin Solid Films $\mathbf{3 1 7}$ April, 1998, pp. 178-182.

40. J. E. Morris, "Recent progress in discontinuous thin metal film devices”, Vacuum $\underline{\mathbf{5 0}}$ (1-2) May/June 1998, pp. 107-113. 